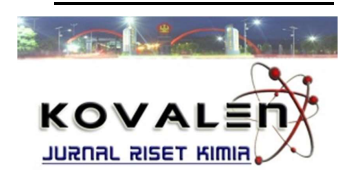

\title{
PROSES KONVERSI MINYAK GORENG BEKAS MENJADI POLIOL SEBAGAI BAHAN BAKU BUSA POLIURETAN
}

\author{
[Conversion Process of Waste Cooking Oil to Polyol as Raw Material in Making \\ Polyurethane Foam]
}

\author{
Estin Nofiyanti ${ }^{1^{*}}$ dan Gatut Ari Wardani ${ }^{2}$ \\ ${ }^{1}$ Program Studi S1 Teknik Lingkungan, Universitas Muhammadiyah Tasikmalaya \\ ${ }^{2}$ Program Studi S1 Farmasi, STIKes Bakti Tunas Husada Tasikmalaya
}

*)Corresponding Author: estin.nofi@umtas.ac.id, hp. 085223486385

Diterima 11 September 2018, Disetujui 25 September 2018

\begin{abstract}
The used frying oil made carcinogenic disease and become the waste contaminating the environment. It has a potency to be used the material in making polyurethane that had economic values. This research aims to convert waste cooking oil into polyol that used as raw material in making polyurethane. The waste cooking oil is converted to polyol through hydroxylation process used formic acid and peroxide. The polyol is reacted with toluene diisocyanate (TDI) and PEG-400. Polyurethane was analyzed used FTIR, determining of density and swelling degrees. The results showed that polyurethane had density of $0.38 \mathrm{~g} / \mathrm{mL}$ and swelling degree of $13.21 \%$.
\end{abstract}

Keywords: waste cooking oil, hidroxylation, polyol, polyurethane

\begin{abstract}
ABSTRAK
Minyak goreng bekas bersifat karsinogenik dan selama ini menjadi limbah yang mencemari lingkungan berpotensi sebagai bahan baku pembuatan busa poliuretan yang bernilai ekonomis. Penelitian ini bertujuan untuk mengkonversi minyak goreng bekas menjadi poliol dan selanjutnya dijadikan sebagai bahan baku busa poliuretan. Minyak goreng bekas dikonversi menjadi poliol melalui proses hidroksilasi menggunakan asam formiat dan asam peroksida. Proses pembuatan poliuretan ini direaksikan dengan Toluen diisosianat (TDI) dan PEG-400. Poliuretan dikarakterisasi menggunakan FTIR, perhitungan massa jenis dan nilai derajat penggembungan. Poliuretan yang terbentuk memeiliki massa jenis sebesar $0,38 \mathrm{~g} / \mathrm{mL}$ dan nilai derajat penggembungan sebesar $13,21 \%$.
\end{abstract}

Kata Kunci : minyak goreng bekas, hidroksilasi, poliol, poliuretan 
LATAR BELAKANG

Minyak goreng apabila digunakan berulang kali maka akan mengalami kerusakan yang disebabkan proses oksidasi dan panas. Minyak goreng yang digunakan berulang-ulang (minyak goreng bekas) bisa menjadi limbah yang berpotensi sebagai bahan pencemar (Naomi et al., 2013, Ningrum \& Kusuma, 2013, Putra et al., 2012). Minyak goreng yang digunakan berulang-ulang akan mempengaruhi kadar dari asam lemak bebas. Suhu penggorengan dapat mengakibatkan perubahan ikatan kimia dari minyak tersebut seperti terjadinya perubahan struktur asam lemak (Priani \& Lukmayani, 2010).

Proses pemanasan yang terjadi dapat mengubah sifat fisika-kimia dari minyak. Pemanasan dapat meningkatkan kadar asam lemak bebas di dalam minyak karena dapat mengakibatkan proses hidrolisis trigliserida minyak berjalan lebih cepat (Mahreni, 2010). Proses pemanasan minyak goreng pada saat digunakan mencapai suhu $160-250{ }^{\circ} \mathrm{C}$ dalam waktu cukup lama, sehingga menyebabkan terjadinya proses oksidasi, hidrolisis, dan polimerisasi yang dapat menghasilkan senyawa-senyawa hasil degradasi minyak. Senyawa-senyawa tersebut dapat merugikan kesehatan manusia seperti keton, aldehid, dan polimer. Kandungan senyawa-senyawa karsinogenik dalam minyak nabati yang telah digunakan lebih dari empat kali sangat membahayakan kesehatan manusia. (Pakpahan et al., 2013).

Salah satu upaya untuk meningkatkan nilai ekonomi minyak goreng bekas menjadi suatu produk yang memiliki nilai jual tinggi adalah dengan menggunakannya sebagai bahan baku pembuatan busa poliuretan. Keuntungan dari proses pembuatan busa poliuretan yang berasal minyak goreng bekas antara lain biaya produksi yang murah dan dapat mengatasi permasalahan lingkungan karena menggunakan bahan baku minyak goreng bekas.

Poliuretan pada umumnya dimanfaatkan sebagai busa, elastomer, lem dan pelapis (Szycher, 2013). Di dunia industri, poliuretan dibuat sebagai bahan isolator panas karena mempunyai konduktivitas rendah (Stevens, 2007). Dalam bidang kedokteran, poliuretan umumnya digunakan sebagai bahan pelindung muka, kantung darah, bahan pelapis dan pembungkus.

Kualitas poliuretan ditentukan dari sumber poliol dari alam dan perbandingan komposisi poliol dengan PEG yang digunakan (Sutiani, 2013). Sifat mekanik poliuretan dapat diperoleh dengan mengubah perbandingan komposisi ($\mathrm{OH} / \mathrm{NCO})$ dan jenis gugus hidroksi dari poliol yang digunakan. Arniza et al., 2015 melakukan sintesis poliuretan dari poliol hasil trans-esterifikasi minyak kelapa sawit.

Pada penelitian ini menggunakan monomer diisosianat berupa toluen 
diisosianat (TDI), sumber poliol berupa minyak goreng bekas yang terhidroksilasi, dan monomer polieter berupa PEG-400 (Polietilen glikol-400). Sintesis poliuretan dilakukan dengan cara memvariasikan komposisi PEG-400 terhadap konsentrasi total reaktan. Penentuan gugus fungsi poliuretan hasil sintesis menggunakan spektrofotometer FTIR, penentuan massa jenis menggunakan piknometer, dan penentuan derajat ikatan silang menggunakan derajat penggembungan

\section{METODE PENELITIAN}

Rancangan penelitian ini adalah penelitian eksperimental, menggunakan minyak goreng bekas dari pedagang gorengan di Kota Tasikmalaya. Penelitian dilakukan dalam 3 (tiga) tahap, yaitu proses hidroksilasi minyak goreng bekas, pembentukan poliuretan, dan karakterisasi poliuretan hasil sintesis.

\section{Bahan dan Peralatan}

Bahan-bahan yang digunakan dalam penelitian ini antara lain Minyak goreng bekas, Asam formiat, asam peroksida, Toluene diisocyanate (TDI), PEG-400. Sedangkan peralatan yang diperlukan antara lain rangkaian alat hidroksilasi minyak goreng bekas, rangkaian alat polimerisasi poliuretan dan alat cetak poliuretan.

\section{Prosedur Penelitian}

Proses hidroksilasi minyak goreng bekas (Tsaniyah dan Baruji, 2008)

Sebagai langkah awal, ukur volume minyak goreng bekas $300 \mathrm{~mL}$, masukkan ke dalam labu leher tiga. Kemudian nyalakan pemanas dan pengaduk, sehingga mencapai suhu $40{ }^{\circ} \mathrm{C}$. Tambahkan sejumlah Asam formiat 90\% sebanyak $412 \mathrm{~mL}$ dan $\mathrm{H}_{2} \mathrm{O}_{2} \quad 50 \%$ sebanyak $38 \mathrm{~mL}$ ke dalam labu leher tiga tersebut. Temperatur reaksi dipertahankan pada $40{ }^{\circ} \mathrm{C}$ dengan mengatur termostat dan aliran pendingin dengan waktu reaksi selama 1,5 jam.

Setelah reaksi selesai, lakukan ekstraksi untuk memisahkan poliol dari campurannya. Masukkan campuran hasil reaksi yang masih panas ke dalam labu pemisah dan tambahkan akuades ke dalamnya. Lakukan pengocokan selama \pm 3 menit. Diamkan hasil ekstraksi tersebut selama \pm 30 menit agar poliol terpisah dari air dan sisa reaktan. Lapisan yang berwarna kuning keruh di bagian atas merupakan poliol dan lapisan putih keruh di bagian bawah merupakan campuran air dan sisa reaktan. Pisahkan lapisan bawah dan lapisan atas. Poliol dicuci dengan akuades dua kali dengan jumlah yang sama dengan proses pemisahan reaktan.

\section{Polimerisasi pembentukan poliuretan (Rohaeti dan Suyanta, 2011)}

Pembentukan poliuretan dilakukan dengan mereaksikan dengan polietilen glikol (PEG-400) dan disimpan pada Erlenmeyer dan TDI juga disimpan pada erlenmeyer dan keduanya dikondisikan pada suhu $25{ }^{\circ} \mathrm{C}$ ke dalam water bath yang dilengkapi thermometer dan sirkulasi 
air. Selanjutnya, dilakukan pengadukan terhadap campuran reaksi selama 20 menit sehingga diperoleh poliuretan precure. Kemudian poliuretan precure dituang di atas cetakan dan dibiarkan mengeras. Poliuretan dikarakterisasi menggunakan FTIR, perhitungan massa jenis dan nilai derajat penggembungan.

\section{HASIL DAN PEMBAHASAN}

\section{Hasil hidroksilasi minyak goreng bekas}

Pembuatan poliol dari minyak goreng bekas memberikan dampak positif terhadap produksi poliuretan (C. Zhang et al., 2015). Salah satunya bisa menekan harga bahan baku poliuretan menjadi lebih murah dan dapat diperbaharui karena berasal dari alam.

Poliol disintesis dari proses hidroksilasi minyak Goreng Bekas dengan asam formiat dan hidrogen peroksida. Poliol yang dihasilkan berupa cairan putih keruh. Gugus fungsi poliol yang dihasilkan dianalisis menggunakan FTIR. Spektra FTIR poliol hasil hidroksilasi minyak Goreng Bekas terdapat pada Gambar 1.

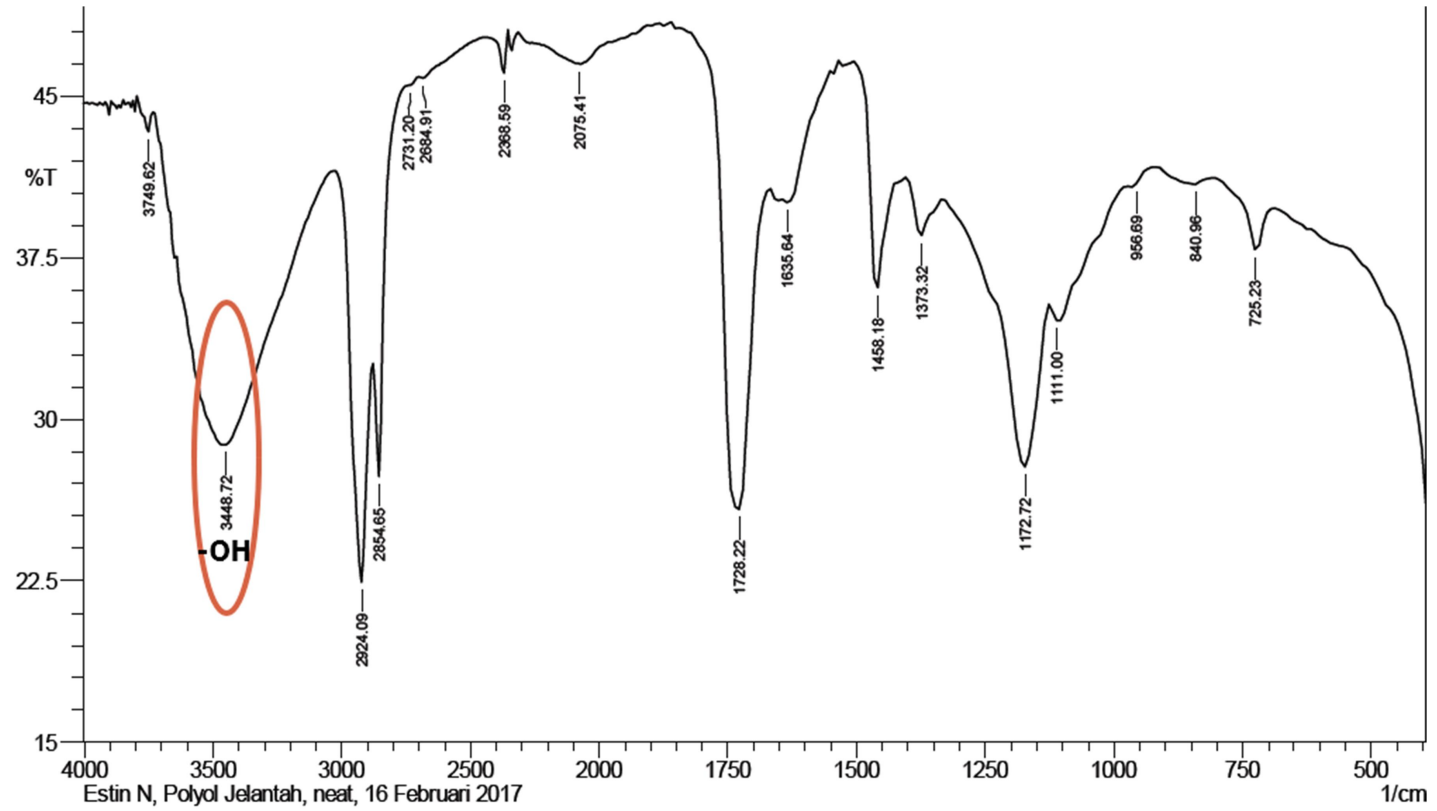

Gambar 1. Spektra FTIR Poliol Hasil Hidroksilasi Minyak Goreng Bekas

Puncak yang lebar pada $3448 \mathrm{~cm}^{-1}$ menunjukkan adanya gugus hidroksil ($\mathrm{OH})$ pada hasil hidroksilasi minyak goreng bekas (Zafiah et al., 2015). Gugus $-\mathrm{OH}$ akan bereaksi dengan diisosianat untuk membentuk polimer poliuretan.

\section{Polimerisasi pembentukan poliuretan}

Spektra FTIR poliuretan Hasil sintesis dari Poliol : TDI : PEG-400 dengan variasi komposisi $2: 1,5: 1$ dapat dilihat pada Gambar 2. Hasil karakterisasi terhadap poliuretan hasil sintesis menggunakan FTIR menunjukkan pita 
serapan pada daerah yang karakteristik untuk poliuretan. Terbentuknya poliuretan ditandai dengan berkurangnya intensitas gugus isosianat $(\mathrm{N}=\mathrm{C}=\mathrm{O})$ dari TDI (Ifa et al., 2008). Spektra FTIR yang diperoleh menunjukkan adanya serapan khas pada $\sim 1735,93 \mathrm{~cm}^{-1}$ merupakan serapan gugus $\mathrm{C}=\mathrm{O}$ uretan. Serapan pada $\sim 2276,00 \mathrm{~cm}^{-1}$ merupakan serapan gugus -NCO. Serapan pada $\sim 3387,00 \mathrm{~cm}^{-1}$ merupakan serapan gugus N-H. Serapan pada 1072 $\mathrm{cm}^{-1}$ menunjukkan adanya serapan C-O.

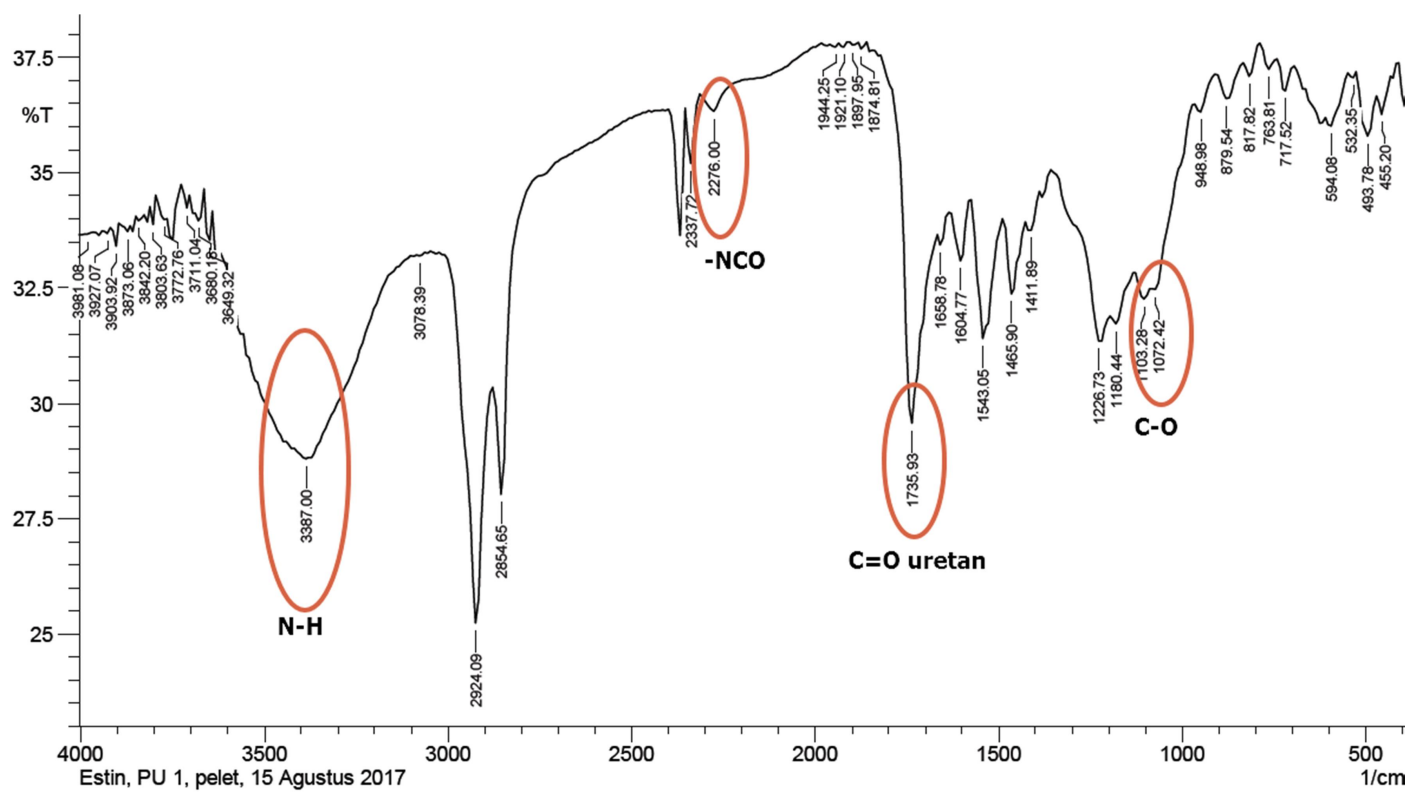

Gambar 2. Spektra FTIR Poliuretan Hasil Sintesis dari Poliol : TDI : PEG-400 (2:1,5:1)

Tabel 1. Massa Jenis Poliuretan Hasil Sintesis

\begin{tabular}{cc}
\hline Komposisi & Massa jenis $(\mathbf{g} / \mathbf{m L})$ \\
Poliol : TDI : PEG-400 & 0,42 \\
$2: 1,5: 0$ & 0,38 \\
$2: 1,5: 1$ & 0,55 \\
$2: 1,5: 2$ & 0,50 \\
$2: 1,5: 3$ & \\
\hline
\end{tabular}

Berdasarkan data massa jenis poliuretan hasil sintesis (Tabel 1) dapat diketahui bahwa massa jenis poliuretan hasil sintesis poliol dan TDI setelah ditambah PEG-400 (2: 1,5:1) mengalami penurunan massa jenis. Penurunan massa jenis ini dapat disebabkan akibat kenaikan volume poliuretan setelah penambahan PEG-400. Massa jenis kembali meningkat setelah penambahan PEG-400 dengan komposisi 2 dan 3. Kenaikan massa jenis diakibatkan volume poliuretan semakin kecil. Penurunan volume poliuretan dapat disebabkan 
kecepatan reaksi pembentukan gas

(blowing reaction). Polimer yang dihasilkan mengeras terlebih dahulu sebelum dapat mengmbang (Anisah et al., 2013).

Hasil dari perhitungan derajat penggembungan dapat dilihat pada Tabel 2. Berdasarkan tabel tersebut diketahui bahwa derajat penggembungan poliuretan hasil sintesis bernilai positif untuk semua variasi komposisi. Derajat penggembungan yang bernilai positif tersebut, maka dalam strukturnya mengandung ikatan silang. Poliuretan dapat menggembung karena molekulmolekul air yang digunakan sebagai pelarut dapat menembus jaringan pada poliuretan hasil sintesis.

Tabel 2. Derajat Penggembungan Poliuretan

\begin{tabular}{cc}
\hline Poliuretan & \%S \\
\hline PU0 & 0 \\
PU1 & 13,21 \\
PU2 & 23,08 \\
PU3 & 15,94
\end{tabular}

\section{KESIMPULAN}

Poliuretan dapat disintesis dari hasil polimerisasi poliol minyak goreng bekas dengan toluene diisocyanate (TDI). Poliuretan yang terbentuk memiliki massa jenis sebesar $0,38 \mathrm{~g} / \mathrm{mL}$ dan nilai derajat penggembungan sebesar $13,21 \%$

\section{UCAPAN TERIMAKASIH}

Terima kasih kepada Kementrian

Rset Teknologi dan Direktorat Jendral Pendidikan Tinggi (KEMRISTEKDIKTI) melalui program Penelitian Dosen Pemula Tahun Anggaran 2017.

\section{DAFTAR PUSTAKA}

Anisah, S., Yahma, M. S., dan Sumarno, 2013, Pengaruh Penggunaan Blowing Agent Methylene Chloride dan Karbondioksida terhadap Struktur Polyurethane Foam, Prosiding Seminar Nasional Taknik Kimia "Kejuangan", C11. 1-3, Yogyakarta: UPN Veteran Yogyakarta.
Arniza, M.Z., S. S. Hoong, Z. Idris, S. K. Yeong, H.A. Hassan, A. K. Din, dan Y. M. Choo, 2015, Synthesis of Transesterified Palm Oil-Based Poliol and Rigid Polyurethanes from this Poliol, J. Am. Oil Chem. Soc., vol. 92, No. 2, 243-255.

C. Zhang, S. A. Madbouly, dan M. R. Kessler, 2015, Biobased Polyurethane Prepared From Different Vegetable Oils, ACS Appl. Mater. Interfaces, Vol. 7, no. 2, pp. 1226-1233.

Ifa, L., Sumarno., Susianto, dan Mahfud, 2008, Pembuatan Flexible Poliurethane Foam dari Poliol Berbasis Minyak Sawit, Jurnal IImiah Sains dan Teknologi, 7, 87-96.

Mahreni, 2010, Peluang dan Tantangan Komersialiasi Biodiesel-Review, Jurnal Eksergi, X, 2.

Naomi, P., Gaol, A. M. L., \& Toha, M. Y. 2013, Pembuatan Sabun Lunak dari Minyak Goreng Bekas Ditinjau dari Kinetika Reaksi Kimia. Jurnal Teknik Kimia, 19(2), 42-48. 
Ningrum, N. P., \& Kusuma, M. A. I. K. 2013, Pemanfaatan Minyak Goreng Bekas dan Abu Kulit Buah Kapuk Randu (Soda Qie) sebagi Bahan Pembuatan Sabun Mandi Organik Berbasis Teknologi Ramah Lingkungan, Jurnal Teknologi Kimia Dan Industri, 2(2), 275-285.

Pakpahan, J. F., Tambunan, T., Harimby, A., \& Ritonga, M. Y. 2013, Pengurangan FFA dan Warna dari Minyak Jelantah dengan Adsorben Serabut Kelapa dan Jerami, Jurnal Teknik Kimia USU, 2(1), 31-36.

Putra, A., Mahrdania, S., Dewi, A., \& Saptia, E. 2012, Recovery Minyak Jelantah Menggunakan Mengkudu Sebagai Absorben, In Prosiding Seminar Nasional PERTETA (pp. 585-589).

Priani, S. E., \& Lukmayani, Y. 2010, Pembuatan sabun transparan berbahan dasar minyak jelantah serta hasil uji iritasinya pada kelinci. In Prosiding SNaPP (pp. 31-48).

Rohaeti, E. dan Suyanta, 2011, Analisis Sifat Termal Poliuretan Berbasis Minyak Jarak dan Toluena Diisosianat dengan Teknik DTA dan TGA, Prosiding, Seminar Nasional Penelitian, Pendidikan dan Penerapan MIPA yang diselenggarakan oleh FMIPA UNY, tanggal 14 Mei 2011, Yogyakarta: Universitas Negeri Yogyakarta

Stevens, Malcolm P., 2007, Terjemahan lis Sopyan, Kimia Polimer, Jakarta : PT Pradnya Paramita.

Sutiani, A., dan Kartika Rizki Bidza, 2013, Pengaruh Variasi Komposisi Gliserol, PEG1000 dan MDI terhadap Sifat Mekanik Perekat Poliuretan, Prosiding Semirata FMIPA UNILA 2013, Lampung.

Szycher, M., 2013, Szycher's Handbook of Polyurethane, Second Edition, CRC Press, Boca Raton, New York.
Tsaniyah, T. A. Dan Teguh Baruji, 2008, Pengaruh Rasio TDI/Polyol Minyak Goreng Bekas dan Penambahan Ethylene Glycol terhadap Kuat Tekan Polyurethane, Makalah dissajikan pada Seminar Tugas Akhir S1 Jurusan Teknik Kimia UNDIP (Unpublished), Semarang.

Zafiah M. Rus, A., Syamimi M. Salim, N., dan Haiza Sapiee, N. 2015, Recycling of Cooking Oil Wastr into Reactive Polyurethane for Blending with Thermoplastic Polyethylene, International Journal of Polymer Science. 1-10. 